\title{
Early and late results of fascia lata transplantation in high myopia
}

\author{
A. P. NESTEROV, N. B. LIBENSON, AND A. V. SVIRIN \\ From the Department of Eye Diseases, 2nd Moscow Medical Institute, USSR
}

In 1970 we described the technique and preliminary results of strengthening the sclera with a strip of fascia lata in progressive myopia (Nesterov and Libenson, 1970). However, our follow-up was limited and the final results were uncertain. The present paper analyses the early and the late results in a group of myopic patients who were followed-up for periods of up to 9 years.

\section{Patients and methods}

The operation was performed on 184 eyes of 108 patients aged from 8 to 52 years. The degree of myopia varied from 7 to 39 dioptres (mean $18 \mathrm{D}), 78$ eyes were astigmatic (more than I.O D cyl.), and 70 had profound degenerative changes of the choroid and the retina. The myopia was definitely progressive in 128 eyes. Reliable information on whether the myopia was progressive or stable was not available in the remaining cases.

Our operation is a modification of that of Shevelev (1930) and Curtin (196I). The technique has been reported in detail elsewhere (Nesterov and Libenson, 1970). Briefly it is as follows. With a fascial stripper a strip of fascia lata $120 \mathrm{~mm}$ long and $6 \mathrm{~mm}$ wide is excised through a $30 \mathrm{~mm}$ incision in the outer surface of the thigh. The strip is cut longitudinally to make a Y-shaped transplant with one broad and two narrow arms. The conjunctival-tenon incisions are made in the superonasal, inferonasal, and temporal quadrants of the eyeball. The lateral rectus muscle is then cut off. With the help of a Curtin hook (Curtin, r96I) the graft is placed behind the globe, its narrow arms running above and below the optic nerve and then through the superonasal and inferonasal incisions. The third, broad arm runs along the horizontal meridian at the temporal side. Each of the arms is fixed to the sclera by two silk sutures. The lateral rectus is resutured to the globe and the conjunctival-tenon incisions are closed with running silk sutures.

\section{Results}

I. EARLY

Three to 4 weeks after the operation visual acuity without correction had improved by 0.02 to 0.14

Address for reprints: A. P. Nesterov, Department of Eye Diseases, 2nd Moscow Medical Institute, Malaja Pirogovscaja Street, Moscow 435, USSR (mean 0.08 ) in $17 \mathrm{I}$ eyes (93 per cent). Visual acuity with correction had improved by 0.1 to 0.2 in 106 eyes ( 58 per cent) and by 0.25 to 0.5 in 45 ( 24 per cent). In one eye, as a result of postoperative uveitis, visual acuity decreased by 0.06 without correction and by 0.3 with correction.

Visual fields were investigated by a kinetic technique with the hemispherical Kugel perimeter. The peripheral boundary of the field was examined $\left(3 / 33^{\circ}\right)$ in 12 directions without glasses and both paracentral and central areas with corrective glasses $(\mathrm{r} / 330)$. Either a concentric or sectorial narrowing of the visual field was found in 177 eyes. It became wider by ro to 25 degrees in at least two directions in 160 cases after surgery. The changes in paracentral and central areas (70 eyes) were stable.

Refractive power was examined with a Hartinger refractometer and sciascopically. Myopia had decreased in 169 eyes ( 92 per cent) by $\mathrm{I}$ to $8 \mathrm{D}$ (mean 3.I D). The power of corrective glasses had decreased by zero to $8 \mathrm{D}$ (mean $3 \cdot 0 \mathrm{D}$ ).

\section{LATE}

Follow-up after operation was for periods of from I to 9 years in 105 eyes (67 patients): from $I$ to 3 years in 56 eyes, from 3 to 5 years in 15 , from 5 to 7 years in 27 , and for more than 7 years in 7 eyes.

The results are summarized in the Table. Visual acuity had improved in 76 eyes ( 72 per cent).

Table Late results of surgery in 105 myopic eyes

\begin{tabular}{|c|c|c|c|c|c|c|}
\hline & \multicolumn{2}{|c|}{ Improved } & \multicolumn{2}{|c|}{ Unchanged } & \multicolumn{2}{|c|}{ Impaired } \\
\hline & No. & $(\%)$ & No. & $(\%)$ & No. & $(\%)$ \\
\hline $\begin{array}{l}\text { Visual acuity } \\
\text { without } \\
\text { correction }\end{array}$ & 76 & (72) & 21 & $(20)$ & 8 & (8) \\
\hline $\begin{array}{l}\text { Visual acuity } \\
\text { with correction } \\
\text { Degree of myopia }\end{array}$ & $\begin{array}{l}76 \\
92\end{array}$ & $\begin{array}{l}(72) \\
(88)\end{array}$ & $\begin{array}{r}23 \\
7\end{array}$ & $\begin{array}{c}(22) \\
(6)\end{array}$ & $\begin{array}{l}6 \\
6\end{array}$ & $\begin{array}{l}(6) \\
(6)\end{array}$ \\
\hline
\end{tabular}


The mean improvement was 0.05 without correction and $0.18(0.03$ to 0.4$)$ with corrective glasses. The degree of myopia had decreased in 92 cases (88 per cent) by 0.5 to $8.5 \mathrm{D}$ (mean $4.2 \mathrm{D}$ ). The power of glasses required decreased in 91 eyes by 0.5 to $6 \mathrm{D}$ (mean $3.8 \mathrm{D}$ ).

The differences between the early and the late results were not notable in 64 eyes (6I per cent). The corrected visual acuity had increased by 0.03 to 0.2 in 35 eyes ( 33 per cent) and decreased by 0.02 to 0.15 in 6 cases (6 per cent).

Comparison of the changes in refractive power of the two eyes in those patients in whom only one eye was operated on was of interest. In 29 cases followed-up for $I$ to 7 years the degree of myopia had risen in only five ( 17 per cent) by 0.5 to $3 \mathrm{D}$ (mean $1.7 \mathrm{D}$ ). In the fellow eye the degree of myopia had increased in 24 cases $(83$ per cent). The average increase in refractive power was $2.9 \mathrm{D}$ (range 1.5 to $6 \mathrm{D}$ ).

Retinal detachment occurred in only one of the ro5 eyes. It was cured by surgery without any change in visual acuity or refractive power. There was no retinal detachment in 29 fellow eyes.

\section{Discussion}

The operative results in these cases show that the risk of complications is small. As a rule the operation halts the progress of the myopia or delays it for several years. In many cases the operation leads to both a decrease in the degree of myopia and an improvement of visual function.

The effect of the operation on the eye can hardly be limited to supporting the posterior sclera with the graft. Two other factors may be involved. Unexpectedly, we found that ocular tension was appreciably lowered after surgery. The mean $( \pm \mathrm{SE}$ of mean) applanation intraocular pressure in 184 eyes was $16.7 \pm 0.31 \mathrm{mmHg}$ before surgery and $14.1 \pm 0.36 \mathrm{mmHg}$ three weeks after surgery
$(P<0.001)$. In 42 eyes that were examined three years or more after surgery the intraocular pressure was $2 \cdot 2 \pm 0.24 \mathrm{mmHg}$ lower and the $\mathrm{C}$-value $0.038 \pm 0.014 \mathrm{~mm}^{3} / \mathrm{min} \mathrm{mmHg}$ higher compared with their preoperative level. These differences are significant $(\mathrm{P}<0.05)$. The reason for the increase in the outflow facility and the decrease in the intraocular pressure is not clear. Perhaps the beneficial effect of the operation on myopia partly depends on a decrease in ocular tension.

Libenson (1967) showed experimentally that a strip of fascia lata transplanted to the eyes of rabbits led to the formation of new blood vessels both in the graft and the neighbouring scleral tissue. Improvement in the blood supply of the posterior sclera is believed to play a part in strengthening scleral tissue.

Thus, the beneficial effect of the operation seems to be due to the support given to the posterior sclera by the fascial graft, the lowering of ocular tension, and the improvement in the blood supply to the scleral tissue.

\section{Summary}

Transplantation of a strip of fascia lata to strengthen the posterior sclera in high progressive myopia was performed on 184 eyes of 108 patients with myopia ranging from 7 to $39 \mathrm{D}$. Three weeks after surgery visual acuity with correction had improved by 0.1 to 0.5 in 151 eyes ( 82 per cent) and refractive power had decreased by $\mathrm{I}$ to $8 \mathrm{D}$ in 169 eyes (92 per cent). In 105 eyes (67 patients) that were followed-up for periods of from I to 9 years myopia increased in six by 0.5 to $3 \mathrm{D}$. In 29 patients who had an operation on only one eye and were then followed-up for periods of from $I$ to 7 years the degree of myopia in the fellow eye increased by $1 \cdot 5$ to $6 \mathrm{D}$ in 24 (83 per cent), and of the eyes that were operated on myopia increased by 0.5 to $3 \mathrm{D}$ in only 5 ( 17 per cent).

\section{References}

CURTIN, B. J. (196r) Amer. Y. Ophthal., 52, 853

LIBENSON, N. B. (1967) In 'Diagnosis and Therapy of Eye Diseases', ed. A. P. Nesterov, pp. I49-15 I. Tatisdat, Kazan

NESTEROV, A. P., and Libenson, N. B. (1970) Brit. F. Ophthal., 54, 46

SHEVELEV, M. M. (1930) Oftal. Zh., 2, 107 